\title{
PROPOSIÇÕES PRELIMINARES PARA ORGANIZAÇÃO DO ENSINO NA PRÉ-ESCOLA
}

\author{
PROPOSICIONES PRELIMINARES PARA LA ORGANIZACIÓN DE LA EDUCACIÓN \\ EN PREESCOLAR
}

\author{
PRELIMINARY PROPOSITIONS FOR THE ORGANIZATION OF PRE-SCHOOL \\ TEACHING
}

\author{
Eliza Maria BARBOSA ${ }^{1}$ \\ Janaina Cassiano SILVA ${ }^{2}$
}

RESUMO: Neste trabalho apresentamos os resultados de uma pesquisa cujo objetivo era revelar os conteúdos ensinados às crianças pré-escolares da rede pública de um município no interior do estado de São Paulo. Participaram do estudo onze instituições, sendo trinta e seis turmas de crianças de quatro anos e trinta e duas turmas de crianças com cinco anos. Foram observadas setenta e duas atividades desenvolvidas pelas professoras de quarta etapa e sessenta e quatro por professoras de quinta. O pressuposto teórico-metodológico está pautado no materialismo histórico-dialético. Este pressuposto compõe uma parte das sínteses teóricas da Psicologia Histórico-Cultural e da Pedagogia Histórico-Crítica, também tomadas nessa pesquisa como fundamentos. Os resultados indicam que os conteúdos ensinados às crianças se concentram em conceitos das diversas áreas do conhecimento, sem que se observe concomitantemente o ensino de conteúdos cujo objetivo é promover o desenvolvimento de novos hábitos, acuidades motoras, perceptivas, mnemônicas, entre outras.

PALAVRAS-CHAVE: Educação infantil. Psicologia histórico-cultural. Ensino. Práticas educativas.

RESUMEN: En este trabajo presentamos los resultados de una investigación cuyo objetivo fue revelar los contenidos que se enseñan a los niños en edad preescolar en el sistema escolar público de una ciudad del interior del estado de São Paulo. En el estudio participaron once instituciones, con treinta y seis clases de niños de cuatro años y treinta y dos clases de niños de cinco años. Se observaron setenta y dos actividades desarrolladas por profesores de cuarta etapa y sesenta y cuatro por profesores de quinta. El supuesto teórico-metodológico se basa en el materialismo histórico-dialéctico. Este supuesto forma parte de las sintesis teóricas de la Psicología Histórico-Cultural y la Pedagogía Histórico-Crítica también tomadas en esta investigación como fundamentos. Los resultados indican que los contenidos enseñados a los niños se concentran en conceptos de diferentes áreas del conocimiento, sin

\footnotetext{
${ }^{1}$ Universidade Estadual Paulista (UNESP), Araraquara - SP - Brasil. Professora Assistente II do Departamento de Psicologia da Educação e Professora do Programa de Pós-graduação em Educação Escolar. Doutorado em Educação Escolar (UNESP). ORCID: https://orcid.org/0000-0002-9452-6008. E-mail: eliza.barbosa@unesp.br ${ }^{2}$ Universidade Federal de Catalão (UFCAT), Catalão - GO - Brasil. Professora Adjunta Curso de Psicologia e no Programa de Pós-Graduação em Educação. Doutorado em Educação (UFSCAR). ORCID: https://orcid.org/0000-0003-1145-5820.E-mail: janacassiano@gmail.com
} 
observar simultáneamente la enseñanza de contenidos cuyo objetivo es promover el desarrollo de nuevos hábitos, habilidades motoras, perceptuales, mnemotécnicas, entre otras.

PALABRAS CLAVE: Educación infantil. Psicología histórico-cultural. La educación. Prácticas educativas.

ABSTRACT: In this work we present the results of a research whose objective was to reveal the contents taught to preschool children in the public school in a city in the interior of the state of São Paulo. Eleven institutions participated in the study, with thirty-six classes of children aged four and thirty-two classes of children aged five. Seventy-two activities developed by fourth-stage teachers and sixty-four by fifth teachers were observed. The theoretical-methodological assumption is based on historical-dialectical materialism. This assumption makes up part of the theoretical syntheses of Cultural-Historical Psychology and Historical-Critical Pedagogy, which were also taken in this research as foundations. The results indicate that the contents taught to children are concentrated on concepts from different areas of knowledge, without simultaneously observing the teaching of contents whose objective is to promote the development of new habits, motor skills, perceptual, mnemonic, among others.

KEYWORDS: Early childhood education. Cultural-historical psychology. Teaching. Educational practices.

\section{Introdução}

O presente texto apresenta os dados e análises de uma pesquisa desenvolvida no período de 2014 a $2018^{3}$, tendo as escolas de Educação Infantil e as práticas educativas de professoras pré-escolares de um município do interior do estado de São Paulo como objeto e campo. A identificação dos conteúdos ensinados e os meios usados para a sua apropriação pelas crianças nos fornece uma caracterização da percepção das professoras a respeito da relação entre o ensino, as aprendizagens e o desenvolvimento das crianças pré-escolares.

Os resultados da pesquisa apontam para dois aspectos fundamentais pertinentes às discussões no campo da Educação Infantil. O primeiro aspecto refere-se à necessidade de desenvolver conteúdos, tanto de natureza teórica (conhecimentos científicos) quanto operacional (formação de hábitos e habilidades), assegurando às crianças não só o domínio de noções iniciais de diferentes áreas de conhecimento, mas também aquelas ligadas à formação de hábitos e domínio de procedimentos (MARTINS, 2009). Como segundo aspecto, indicamos que o ensino de crianças pré-escolares, estruture-se considerando a atividade

3 "Aprendizagem versus ensino na educação infantil: falsa oposição ou caminho para a consolidação de uma didática pré-escolar?", foi desenvolvida com financiamento obtido pelo Edital de Apoio a Projetos de Pesquisa / Chamada MCTI/CNPQ/MEC/CAPES No 22/2014 - Ciência Humanas, Sociais e Sociais Aplicadas.

RPGE- Revista on line de Política e Gestão Educacional, Araraquara, v. 25, n. 1, p. 267-281, jan./abr. $2021 . \quad$ e-ISSN:1519-9029 
principal característica da periodização do desenvolvimento, assegurando a consolidação de práticas educativas comprometidas com o processo de humanização das crianças.

Este artigo está dividido em três partes. Na primeira apresentamos o número de instituições e turmas de educação infantil que compõem a amostra e uma caracterização do atendimento e estruturação da rede municipal, carreira e jornada das professoras e os pressupostos orientadores de suas práticas educativas. Na sequência analisamos os dados referentes aos conteúdos ensinados às crianças pré-escolares e ao final refletimos sobre consolidação de um ensino que tome a atividade principal, guia do desenvolvimento em cada etapa, como um de seus princípios fundamentais de organização. As reflexões são mediadas teoricamente pelas contribuições da Psicologia Histórico-Cultural e da Pedagogia HistóricoCrítica.

\section{Traços gerais da pesquisa}

O município pesquisado tem quarenta e duas instituições de Educação Infantil atendendo, no mesmo equipamento físico, as crianças de creche e pré-escola. No ano de 2017, a rede atendia em torno de dez mil crianças, aproximadamente mil bebês em idade de até dois anos e, das crianças pré-escolares, menos de $1 / 3$ são de período integral. O cuidado e educação das crianças menores de dois anos é realizado por profissionais leigos, não pertencentes à carreira do magistério. Com as crianças de aproximadamente dois anos e meio até os seis, o trabalho educativo é feito por pedagogas aprovadas por concurso público. As professoras e professores do município possuem uma jornada de vinte quatro horas semanais, sendo vinte em exercício docente, duas horas de HTPC (Hora de Trabalho Pedagógico Coletivo) e duas de HTPI (Hora de Trabalho Pedagógico Individual). As turmas não excedem o número de vinte cinco crianças e onde há crianças com deficiência, esse número cai para dezoito e há um agente técnico acompanhando o docente.

Um estudo sobre a carreira e condições de trabalho das professoras pré-escolares deste município, realizado por Alvarenga (2012) indicou uma realidade diversa da maioria dos demais municípios brasileiros, visto que um expressivo investimento na criação de políticas públicas consistentes, entre as décadas de 1980 e 1990, lograram condições de trabalho e um Plano de Carreiras, Cargos e Vencimentos cujo pioneirismo é até hoje reconhecido, se considerarmos as exigências quanto ao nível de formação profissional docente, a infraestrutura das instituições e a oferta de cursos de formação continuada oferecidos por uma equipe técnica especializada. 
Do ponto de vista da estruturação curricular, o município possui um documento oficial: Orientações Curriculares da Pré-escola (2011), constituído por princípios teóricos e conceituais sobre: infância; relação entre desenvolvimento e aprendizagem; necessidades educativas; função da educação infantil e conteúdos divididos nas seguintes áreas: Conhecimento de Si e do Mundo; Linguagem Oral e Escrita; Linguagem Matemática; Natureza e Sociedade e Arte, seguindo as áreas encontradas no Referencial Curricular Nacional para Educação Infantil.

Sinteticamente podemos definir que seu referencial teórico resulta de um hibridismo entre os pressupostos do construtivismo, especialmente a compreensão de que a aprendizagem infantil resulta da experiência individual e espontânea das crianças e os pressupostos dos autores da Pedagogia da Infância, particularmente a defesa de que os conhecimentos socializados devem privilegiar os conteúdos que emergem da inter-relação cotidiana entre crianças e adultos, além de práticas situadas nos cuidados e outras formas de inserção e manifestação social das crianças nas relações culturais, sociais e familiares.

Embora a confluência desses aspectos que acabamos de discutir com os demais dados que a pesquisa nos revela indique a existência de aspectos estruturais e pedagógicos bastante consolidados por essa rede, destacamos as análises alguns avanços que consideramos comuns às redes públicas de ensino, sobretudo quando se trata de estabelecer as finalidades educativas e políticas para a formação das novas gerações. Os resultados da pesquisa corroboram os argumentos construídos desde a década de oitenta em defesa da educação pré-escolar.

Campos (1997) ao apresentar um panorama das pesquisas sobre creches e sua relação com a pré-escola, na América Latina e no Brasil, apresenta-nos resultados conclusivos a respeito da importância da pré-escola. Na América Latina, os estudos apresentados pela autora, indicam um grande impacto sobre o desenvolvimento cognitivo das crianças que frequentavam os chamados jardins de infância. No Brasil, por sua vez, uma amostra de crianças que frequentavam a terceira série do ensino fundamental, no ano de 1985, nas capitais nordestinas de Fortaleza e São Luís, revelou que por serem egressas da pré-escola "encurtou em meio ano a duração do percurso escolar dos alunos nas três séries consideradas" (CAMPOS, 1997, p. 123).

Abramovay e Kramer (1991) em artigo produzido há três décadas, defenderam tratarse de uma ingenuidade política e ideológica condicionar a solução da carência cultural de crianças pobres e os altos índices de repetência no ensino de $1^{\circ}$ grau ao pré-escolar. Ao mesmo tempo, alertavam para o risco de esvaziamento da função deste, pois, com objetivos em si mesmo e sem relação com o ensino de $1^{\circ}$ grau, a educação pré-escolar poderia 
facilmente caracterizar-se por práticas informais, assistemáticas e sem exigência de qualidade. As autoras esclarecem, "não negamos os objetivos imediatos da pré-escola. Longe estamos de subestimar sua função para o desenvolvimento infantil. No entanto, descaracterizar a relação pré-escola/escola é evitar discutir a qualidade que essa pré-escola deve ter" (ABRAMOVAY; KRAMER, 1991, p. 33).

Mais recentemente, embora permaneçam divergências a respeito da especificidade e função da Educação Infantil, construiu-se um consenso a respeito da importância das experiências educativas proporcionadas às crianças menores de seis anos pelas diversas áreas que servem de fundamento para a Pedagogia, com destaque para os estudos teóricometodológico sustentados nos pressupostos da Psicologia Histórico-Cultural e da Pedagogia Histórico-Crítica, para os quais as práticas escolares devem promover nas crianças as suas "máximas possibilidades de desenvolvimento" (MARTINS, 2009, p. 93).

Com base nesses pressupostos, discutiremos a seguir sobre a necessidade identificada na pesquisa de promover escolhas curriculares que contemplem tanto os conteúdos de natureza teórica (conhecimentos científicos), quanto operacionais (formação de hábitos e habilidades), assegurando às crianças o domínio de noções iniciais de diferentes áreas de conhecimento, bem como aquelas ligadas à formação de hábitos e domínio de procedimentos (MARTINS, 2009).

\section{Traços de uma realidade: os conteúdos ensinados na pré-escola visitada}

A amostra da pesquisa corresponde a observação e registro de trinta e seis episódios das práticas de professoras de crianças de quatro anos de idade, cujo agrupamento é denominado $4^{\mathrm{a}}$ etapa, e trinta e duas professoras de crianças de cinco anos, agrupamento chamado de $5^{\text {a }}$ etapa. Essas sessenta e oito turmas pertencem a onze instituições de Educação Infantil que são denominadas Centros de Educação e Recreação. Os dados foram coletados entre os meses de Fevereiro e Outubro de 2017, observando-se a rotina diária das atividades realizadas do início ao final dos períodos matutino ou vespertino. O horário do período matutino é de $7 \mathrm{~h} 30$ às $11 \mathrm{~h} 30$ e do vespertino das $13 \mathrm{~h}$ às $17 \mathrm{~h}$. Foram anotadas somente as atividades constantes nos planejamentos das professoras, sendo que as demais são consideradas atividades livres, sem que a professora tenha estabelecido algum objetivo para sua realização. Observamos duas atividades de cada professora respeitando a separação de três meses entre uma atividade e outra. Isso significa que se primeira atividade de uma turma foi observada em Fevereiro, a segunda ocorreu em Maio. Por sua vez, quando a primeira 
observação ocorreu em Junho a segunda se deu Outubro, excetuando o recesso do mês de Julho. Tal iniciativa se justifica para termos um retrato mais fiel da dinâmica dada ao ensino pelas professoras.

Como será possível notar, os dados correspondentes aos conhecimentos ensinados às crianças concentram-se no que Martins (2009) chamou de conhecimentos de natureza teórica. Segundo a autora, tais conhecimentos correspondem àqueles extraídos diretamente das diferentes áreas do conhecimento, tais como: português, matemática, ciências, história, geografia e arte. Estes conhecimentos, quando ensinados, incidem diretamente na aprendizagem das crianças e indiretamente em seu desenvolvimento. Entretanto, Martins (2009) nos lembra que, independentemente da faixa etária que atende, à escola cabe a função de transmitir a cultura para além das esferas cotidianas. Para isso, as práticas educativas escolares, além de assegurar que os conhecimentos científicos tornem-se presentes no ensino das crianças menores de seis anos, devem ocupar-se também em promover os conteúdos que incidem de modo direto no desenvolvimento das crianças, acrescentando-lhes novos hábitos e habilidades tais como: "autocuidados; hábitos alimentares saudáveis; destreza psicomotora; acuidade perceptiva e sensorial; habilidades de comunicação significativa; identificação de emoções e sentimentos; vivência grupal; dentre outras" (MARTINS, 2009, p. 95).

A tabela e o quadro abaixo demonstram o total de atividades observadas em cada agrupamento e a natureza dos conteúdos ensinados às crianças.

Tabela 1 - Áreas de conhecimento e o número de atividades observadas

\begin{tabular}{c|c|c|c|c|c|c}
\hline Turma & $\begin{array}{c}\text { Conhecimento de Si } \\
\text { e do Mundo }\end{array}$ & $\begin{array}{c}\text { Linguagem } \\
\text { Oral e Escrita }\end{array}$ & $\begin{array}{l}\text { Linguagem } \\
\text { Matemática }\end{array}$ & $\begin{array}{c}\text { Natureza e } \\
\text { Sociedade }\end{array}$ & Arte & Total \\
\hline $4^{\text {a } \text { etapa }}$ & 8 & 28 & 17 & 6 & 13 & $\mathbf{7 2}$ \\
\hline $5^{\text {a }}$ etapa & 4 & 32 & 12 & 4 & 12 & $\mathbf{6 4}$ \\
\hline
\end{tabular}

Fonte: Elaboração das autoras

Quadro 1 - Áreas de conhecimento e os conteúdos das atividades observadas

\begin{tabular}{|c|c|c|c|c|c|}
\hline Turma & $\begin{array}{l}\text { Conhecimento de } \mathrm{Si} \\
\text { e do Mundo }\end{array}$ & $\begin{array}{l}\text { Linguagem Oral e } \\
\text { Escrita }\end{array}$ & $\begin{array}{l}\text { Linguagem } \\
\text { Matemática }\end{array}$ & $\begin{array}{l}\text { Natureza } \\
\text { Sociedade }\end{array}$ & Arte \\
\hline \multirow[t]{3}{*}{$\begin{array}{c}4^{a} \\
\text { etapa }\end{array}$} & $\begin{array}{ll}\text { Conhecimento da } \\
\text { família: perceber as } \\
\text { composições } \\
\text { familiares (4) }\end{array}$ & $\begin{array}{l}\text { Reconhecer o nome e } \\
\text { alfabeto; (13) }\end{array}$ & $\begin{array}{l}\text { Posição: Frente, atrás, } \\
\text { antes, depois; (5) }\end{array}$ & $\begin{array}{l}\text { Elementos } \quad \mathrm{da} \\
\text { natureza- } \mathrm{Ar} ; \\
(3)\end{array}$ & $\begin{array}{l}\text { Desenho livre; } \\
\text { (7) }\end{array}$ \\
\hline & $\begin{array}{ll}\text { Reconhecimento do } \\
\text { Outro (2) }\end{array}$ & $\begin{array}{l}\text { Consciência } \\
\text { fonológica: diferenças } \\
\text { e semelhanças sonoras; } \\
\text { (11) }\end{array}$ & $\begin{array}{l}\text { Trabalhando } \quad \text { com } \\
\text { números de } 1 \text { a } 6 ;(8)\end{array}$ & $\begin{array}{l}\text { Cores primárias } \\
\text { e secundárias; } \\
\text { (2) }\end{array}$ & $\begin{array}{l}\text { Desenho } \\
\text { orientado; (3) }\end{array}$ \\
\hline & $\begin{array}{l}\text { Diferentes espaços da } \\
\text { escola (2) }\end{array}$ & $\begin{array}{l}\text { Perceber relação } \\
\text { fonema/grafema; (4) }\end{array}$ & $\begin{array}{l}\text { Noções de tempo: dia, } \\
\text { semana, mês e ano; }\end{array}$ & $\begin{array}{l}\text { Sistema } \\
\text { respiratório - os }\end{array}$ & $\begin{array}{l}\text { Apreciação } \\
\text { estética (3) }\end{array}$ \\
\hline
\end{tabular}




\begin{tabular}{|c|c|c|c|c|c|}
\hline & & & (3) & pulmões; (1) & \\
\hline & & & $\begin{array}{ll}\text { Acréscimo } & \mathrm{e} \\
\text { decréscimo (1) }\end{array}$ & & \\
\hline \multirow[t]{4}{*}{$\begin{array}{c}5^{\mathbf{a}} \\
\text { etapa }\end{array}$} & $\begin{array}{lr}\text { Construção } & \mathrm{e} \\
\text { ampliação } & \mathrm{da} \\
\text { autonomia; (2) } & \end{array}$ & $\begin{array}{l}\text { Reconhecer o nome e } \\
\text { alfabeto; (18) }\end{array}$ & Quantificar; (5) & $\begin{array}{l}\text { Árvores } \\
\text { frutíferas; (2) }\end{array}$ & $\begin{array}{l}\text { Expressão } \\
\text { Gráfica } \quad- \\
\text { Desenho (4) }\end{array}$ \\
\hline & $\begin{array}{l}\text { Localização } \\
\text { geográfica: o que tem } \\
\text { no bairro; (2) }\end{array}$ & $\begin{array}{l}\text { Gêneros textuais - } \\
\text { Parlenda (2) }\end{array}$ & $\begin{array}{l}\text { Correspondência } \\
\text { um a um; (3) }\end{array}$ & $\begin{array}{l}\text { Chuva (ciclo da } \\
\text { água); (2) }\end{array}$ & $\begin{array}{l}\text { Produção } \\
\text { de fantoche (2) }\end{array}$ \\
\hline & & $\begin{array}{l}\text { Escrita - formação de } \\
\text { palavras (5) }\end{array}$ & $\begin{array}{l}\text { Reconhecer os } \\
\text { números; (4) }\end{array}$ & & $\begin{array}{l}\text { Colagem } \mathrm{e} \\
\text { pintura com } \\
\text { diferentes } \\
\text { materiais (6) }\end{array}$ \\
\hline & & $\begin{array}{l}\text { Consciência } \\
\text { fonológica: diferenças } \\
\text { e semelhanças sonoras; } \\
\text { (7) }\end{array}$ & & & \\
\hline
\end{tabular}

Fonte: Elaboração das autoras

Os conteúdos das atividades observadas, em certa medida, revelam a persistência da função preparatória e, em oposição a ela, retomamos, seguindo a tradição de compreender um fenômeno pela forma como ele se apresenta ao longo da história, a discussão de Abramovay e Kramer (1991), na qual se buscava um consenso quanto à função da educação pré-escolar que não condenasse as crianças a uma escolarização limitada à experiências informais e não antecipasse toda a carga de atividades características da alfabetização. Esses conteúdos evidenciam uma continuidade com a realidade encontrada em pesquisas realizadas nesta mesma rede municipal, cujos dados são 2005/2006, realizada por Barbosa (2008). A pesquisa sintetiza um panorama extenso dos elementos teóricos e pedagógicos orientadores das práticas docentes, indicando a adesão a uma perspectiva pedagógica orientada pelo critério etário e pelos interesses das crianças. Por sua vez, a pesquisa de Silva e Hai (2012), cujos dados são de 2008, neste mesmo município, teve como objetivo revelar as práticas educativas desenvolvidas com as crianças de até três anos. Os resultados apontam para a prevalência de proposições pedagógicas e práticas espontaneístas, objetivos e conteúdos não estão demonstrados e o planejamento reduz-se às atividades de cuidado.

Podemos dizer que as pesquisas de Barbosa (2008) e Silva e Hai (2012) ressaltam os elementos da relação entre o conhecimento escolar e as finalidades educativas, explicitando o projeto de formação que as instituições estão desenvolvendo com as crianças da educação infantil. Entretanto, esses conteúdos observados em 2017 indicam um avanço, em relação ao que revela Barbosa (2008), quanto ao número de atividades planejadas intencionalmente pelas professoras pré-escolares, visto que no panorama anterior, dois terços das atividades que 
compunham a rotina das crianças nas turmas de pré-escola eram livres e seus objetivos não eram explicitados.

Em síntese, concluímos que muito embora alguns conteúdos teóricos estejam sendo intencionalmente ensinados às crianças, os conteúdos de natureza operacional, componentes fundamentais na formação integral das crianças, não estão presentes. Saviani (2012) ao definir a natureza e a especificidade do trabalho educativo, nos diz que sua natureza é não-material pois está ligada à produção de ideias, conceitos e hábitos e sua especificidade se define pela transmissão do saber historicamente acumulado, com o objetivo de produzir intencionalmente, em cada indivíduo da espécie humana, as capacidades socialmente desenvolvidas pelo conjunto dos homens, cujos resultados se encontram sintetizado na Arte, nas Ciências e na Filosofia. Nesse intento, o autor afirma que o objeto da educação exige, além da identificação dos elementos culturais que precisam ser ensinados às crianças, decidirem sobre as melhores formas de ensiná-las. Para a escolha dos conteúdos, Saviani (2012, p. 13) indica-nos a necessidade de privilegiar os conhecimentos clássicos entendendoos como aquilo que se "[...] firmou como fundamental, como essencial".

Para nós, refletir sobre a especificidade da infância em circunstâncias escolares e a sobre finalidade da educação pré-escolar inclui reconhecer como clássico e essencial a promoção intencional de atividades que se ocupem também do desenvolvimento de conteúdos de natureza operacional. A tendência em privilegiar os conteúdos teóricos em contraposição àqueles ligados a novos domínios motores, afetivos e acuidades sensoriais e perceptivas, embora possa ser explicada pela marca histórica da pré-escola em preparar para o ensino fundamental, deve ser confrontada com a compreensão de que um bom currículo para a préescola será aquele que melhor integrar esses dois tipos de conhecimentos, considerando que quanto menor forem as crianças, mais investimentos devem ser feitos no ensino dos conteúdos operacionais, sobretudo porque seu funcionamento psíquico atual não the capacita para o domínio dos conceitos abstratos próprios dos conteúdos teóricos (MARTINS; PASQUALINI, 2020)

Com o objetivo de contribuir para o aperfeiçoamento desta realidade identificada, refletimos, a seguir, em uma alternativa para a organização do ensino que favoreça a aprendizagem das crianças e a sua consequente influência sob os domínios gerais do desenvolvimento infantil. Para isso, consideramos a atividade principal própria de cada período das crianças como um âmbito estruturante do planejamento e da organização do ensino pré-escolar. 


\section{A linguagem e a atividade principal como elementos estruturantes do ensino pré-escolar}

Os recursos e/ou meios pedagógicos utilizados pelas professoras, para o ensino dos conhecimentos presentes nas atividades que compõem a amostra, estão caracterizados a seguir e ressaltam o predomínio da fala das professoras em relação a outros meios. Os objetos pedagógicos correspondem a materiais como fichas de palavras, material dourado, alfabetos móveis e figuras geométricas.

Quadro 2 - Objetos e recursos usados pelas professoras no desenvolvimento das atividades observadas

\begin{tabular}{|c|c|c|c|c|c|}
\hline \multicolumn{6}{|c|}{$4^{a}$ etapa } \\
\hline \multirow[t]{4}{*}{ Áreas } & $\begin{array}{l}\text { Conhecimento de } \\
\text { Si e do Mundo }\end{array}$ & $\begin{array}{l}\text { Linguagem } \\
\text { Oral e Escrita }\end{array}$ & $\begin{array}{l}\text { Linguagem } \\
\text { Matemática }\end{array}$ & $\begin{array}{l}\text { Natureza } \\
\text { Sociedade }\end{array}$ & Arte \\
\hline & Fala (6) & Fala (26) & Fala (15) & Fala (4) & Fala (10) \\
\hline & $\begin{array}{l}\text { Objetos pedagógicos } \\
(2)\end{array}$ & $\begin{array}{ll}\text { Imagens } & \text { ou } \\
\text { gravuras (2) }\end{array}$ & $\begin{array}{l}\text { Objetos } \\
\text { pedagógicos (2) }\end{array}$ & $\begin{array}{l}\text { Objetos } \\
\text { pedagógicos (2) }\end{array}$ & Objetos pedagógicos (2) \\
\hline & & & & & Imagens ou gravuras (1) \\
\hline \multicolumn{6}{|c|}{$5^{\mathrm{a}}$ etapa } \\
\hline & Fala (4) & Fala (27) & Fala (9) & Fala (3) & Fala $(07)$ \\
\hline & & $\begin{array}{ll}\text { Imagens } & \text { ou } \\
\text { gravuras (3) }\end{array}$ & $\begin{array}{l}\text { Objetos } \\
\text { pedagógicos (3) }\end{array}$ & $\begin{array}{l}\text { Objetos } \\
\text { pedagógicos (1) }\end{array}$ & $\begin{array}{l}\text { Imagens ou gravuras } \\
(03)\end{array}$ \\
\hline & & $\begin{array}{l}\text { Objetos } \\
\text { pedagógicos (2) }\end{array}$ & & & Objetos pedagógicos (2) \\
\hline
\end{tabular}

Fonte: Elaboração das autoras

É legítimo o uso predominante da fala pelas professoras como recurso principal para o ensino, pois essa é a principal via de entrada da criança no mundo social, mas também porque a linguagem do adulto apropriada pela criança é estruturante de todas as funções psicológicas humanas. Para nós, essa perspectiva da linguagem como instrumento fundamental de comunicação, intercâmbio social e reguladora das condutas conscientes infantis, associada à observância das contribuições teóricas extraídas do conceito de atividade principal preconizada pela Psicologia Histórico-Cultural, constitui um terreno fértil para as reflexões sobre a didática pré-escolar, num cenário cuja concepção predominante, preconiza a defesa de processos espontâneos de aprendizagem das crianças e o ensino, como atividade horizontalizada, comportando uma imprevisibilidade necessária para acolher os interesses das crianças por determinados temas ou conteúdos.

Segundo os estudos da Psicologia Histórico-Cultural, o homem realiza atos involuntários (reflexivos) e atos voluntários (conscientes), sendo os últimos definidos pela capacidade humana de estabelecer e cumprir ações a partir da instrução verbal. Para Luria (1986) a explicação científica do ato voluntário deve basear-se na análise do desenvolvimento 
linguístico da criança e sua essência reside nas formas sociais de comportamentos. $\mathrm{O}$ ato voluntário se inicia através da subordinação da criança à instrução verbal do adulto, para posteriormente se transformar em um processo interno, autorregulado. Aos quatro anos, aproximadamente, a conduta que antes era regulada externamente sob a instrução do adulto, passa a regular-se pela linguagem exterior da própria criança, numa unidade entre a fala e as ações. Finalmente, no estágio posterior, essa linguagem externa se internaliza, constituindo as estruturas básicas de seu pensamento.

Semelhante ao desenvolvimento da conduta voluntária, a fala do adulto e depois a fala internalizada da própria criança é precursora do desenvolvimento de funções como a própria linguagem, o pensamento, a atenção, a memória, a imaginação, entre outras. Esse desenvolvimento dependente das possibilidades de mediação simbólicas que a fala do adulto oferece às crianças, conduzindo aquelas funções a um nível superior. Tais evidências teóricas sugerem que a fala das professoras concorre para uma efetiva aprendizagem das crianças, de conteúdos culturais que asseguram a continuidade de sua humanização, pois acrescenta-lhes características do funcionamento psíquico não presentes no nascimento.

Certamente outros objetos pedagógicos dispostos pelas professoras requalificam as mediações interpostas para a consolidação da conduta voluntária que encontra no interior das ações de manipulação de objetos, sejam eles materiais ou simbólicos e nas condutas na atividade de jogos de papéis sociais, uma ampliação do processo de consciência sobre a realidade que ocorrerá suportada na atividade que lhe é própria. Com isso estamos defendendo que a organização do ensino pré-escolar se atente a contribuições pedagógicas que podem ser extraídas dos princípios psicológicos de atividade principal, amplamente discutida pela Psicologia Histórico-Cultural. Para essa teoria, a explicação sobre a gênese e desenvolvimentos dos processos conscientes no homem devem ser buscada na relação entre a atividade produtiva humana, o trabalho e a linguagem (LURIA, 1986).

Para Vygotski (2006), em cada etapa da idade encontramos sempre uma nova formação central (atividade principal), como uma espécie de guia para todo o processo do desenvolvimento que caracteriza a reorganização de toda a personalidade da criança sobre uma base nova. Ao redor dessa nova formação central ou básica da idade apresentada se situam e agrupam as restantes novas formações parciais, relacionadas com facetas isoladas da personalidade da criança, assim como os processos de desenvolvimento relacionados com compreender o desenvolvimento infantil de forma adequada, se o analisarmos a partir do desenvolvimento da atividade, tal como ela se forma nas condições concretas de vida da criança e o papel desempenhado pela linguagem. Contudo, a vida ou a atividade em conjunto 
não se formam mecanicamente, a partir de tipos isolados de atividade. Alguns tipos de atividade são, numa dada etapa, principais e têm grande importância para o desenvolvimento ulterior da personalidade (ELKONIN, 1987).

A atividade principal apresenta três características básicas: é no interior desta atividade que surgem e se diferenciam outros tipos de atividades; é na atividade principal que os processos psíquicos particulares tomam forma ou são reorganizados e; da atividade principal resultam, de forma mais íntima, as principais mudanças psicológicas na personalidade infantil (LEONTIEV, 2006a). Elkonin (1999) afirma que desde o nascimento até a idade adulta, temos as seguintes atividades principais para cada estágio: a comunicação emocional do bebê; atividade objetal manipulatória; brincar/jogo de papéis sociais; atividade de estudo; comunicação íntima pessoal e atividade profissional/estudo. As crianças entre quatro e cinco anos de idade, que compõem os agrupamentos pesquisados, se situam no período em que a atividade principal é a atividade manipulatória em transição para a atividade de jogos de papéis sociais, com predomínio desta última entre as crianças de cinco anos.

Elkonin (2009, p. 215) afirma que a atividade com os objetos é a premissa da aprendizagem de "ações planejadas pela sociedade", pois, a novidade que as crianças buscam compreender nessa manipulação modifica os tipos de relações mantidas com os adultos e dela surgirão tipos diversos de atividades. A comunicação com os adultos, limitada a uma finalidade predominantemente prática na atividade de Comunicação Emocional, modifica-se na atividade Manipulatória, pois, o adulto passa agora à condição de "depositário de modelos de ações com os objetos" (ELKONIN, 2009, p. 215).

No texto de Barbosa, Escudeiro e Silva (2016) encontramos uma análise que evidencia a fertilidade de ações pedagógicas orientadas pelo princípio que considera a atividade principal da criança como um âmbito relevante para as decisões sobre a organização do ensino. Trata-se de apresentação e análise de uma sequência didática desenvolvida com crianças de três e quatro anos de idade da mesma rede do munícipio de nossa pesquisa, que teve como propósito desenvolver o desenho do esquema corporal. O trabalho demonstra que as sucessivas atividades que incluíam a manipulação de objetos tais como bonecos, imagens de partes do corpo, modelagem, construções, recorte e colagem, contribuíram para um expressivo avanço na representação de si pelas crianças. Tal análise corrobora com a defesa de que as mediações com maior valor pedagógico são aquelas que ocorrem quando as crianças produzem a cadeia de ações próprias de sua atividade.

Para Elkonin (2009), a atividade manipulatória funda as premissas para a atividade seguinte de Jogos de Papéis Sociais ou Jogo Protagonizado, na qual se observa o 
desenvolvimento progressivo de ações lúdicas com os objetos e sua substituição por outros não presentes. Assim, de acordo com os preceitos teóricos de Elkonin (2009) e Leontiev (2006b), na idade pré-escolar o desenvolvimento infantil ocorre sob a influência dos jogos de papéis como atividade guia ou principal. Isso quer dizer, segundo Leontiev (2006b), que é por meio da atividade de jogos de papéis ou protagonizados, que as crianças produzem sua existência coletiva, subjetivamente incorporando às suas ações e relações novas habilidades, objetos, aptidões e faculdades. Elkonin (2009) destaca que na passagem do jogo com os objetos, atividade guia anterior, para o jogo protagonizado a transformação não se dá por uma mudança na quantidade ou qualidade dos objetos disponíveis à manipulação das crianças, nem tampouco pelos traços das ações iniciais observadas nessa nova atividade, tal transformação ocorre porque as crianças que antes agiam com os adultos, percebem que podem agir como eles e nesse sentido, [...] "todos os objetos e atos com eles realizados estão agora inseridos num novo sistema de relações da criança com a realidade, numa nova atividade de sensações prazerosas" (ELKONIN, 2009, p. 404).

Os diferentes espaços da educação infantil são cenários cotidianos para o aparecimento dos jogos protagonizados, que em muitos casos estende-se por vários dias. Entretanto, esses jogos surgem e se desenrolam sem planejamento ou intervenções pedagógicas que poderiam resultar em uma ampliação dos processos conscientes de compreensão da realidade pelas crianças, desvelando-se para elas, por exemplo, as relações de dominação e expropriação próprias das sociedades capitalistas. Nesse sentido, temos defendido que as contribuições que os jogos protagonizados dão ao desenvolvimento psíquico das crianças seja objeto de discussão com professoras pré-escolares, tendo em vista também a necessidade de desnaturalizar a brincadeira ${ }^{4}$ como uma atividade própria e natural das crianças.

Ao tomarmos os pressupostos da Psicologia Histórico-Cultural a respeito das atividades principais como organizadores das atividades de ensino, buscamos avançar na proposição de práticas educativas que considerem que a atividade é o elemento que liga o ser ao mundo social e a compreensão dos processos de apropriação, implica em considerar não só o lugar ocupado pela criança na sociedade, mas compreender que cada período conquistado

\footnotetext{
${ }^{4}$ Em nossa experiência observamos que este termo designa, para a maioria das professoras pré-escolares, uma profusão de ações que vão desde as manipulações com objetos tais como chocalhos pelos bebês, passando por todas as formas de uso de brinquedos, jogos tradicionais com ou sem regras, jogos de movimento, chegando até os jogos protagonizados, onde os objetos embora presentes, secundarizam-se em relação à recente necessidade das crianças de conhecer as funções dos adultos e suas atividades.

RPGE- Revista on line de Política e Gestão Educacional, Araraquara, v. 25, n. 1, p. 267-281, jan./abr. $2021 . \quad$ e-ISSN:1519-9029 
pela criança é determinado pelas suas relações socioculturais, especialmente pelo modo como a escola cumpre sua função precípua de humanização das crianças.

\section{Considerações finais}

Reiteramos, ao final da pesquisa, a necessidade premente de investimento na sólida formação teórica das professoras pré-escolares como tessitura para o desenvolvimento de práticas educativas que, ao considerar as especificidades das crianças sublinhe os conteúdos culturais teóricos das áreas do conhecimento, sem, no entanto, promovê-los sobre a perspectiva de uma escolarização precoce das crianças, própria da histórica concepção de préescola preparatória e, concomitantemente, dê aos conteúdos operacionais uma configuração não pragmática, pois quando falamos do desenvolvimento de novas habilidades, acuidades perceptivas e mnemônicas, formação de hábitos, referimo-nos a ações tipicamente humanas não consolidadas por meio de rotinas de cuidado ou repetição de rituais, próprias da concepção de guarda prevalecente na origem das instituições infantis brasileiras, cujos traços ainda são frequentemente encontrados.

Buscamos, com base na totalidade revelada pelos dados da pesquisa, apontar elementos teóricos, bem formulados no campo psicológico, como pressupostos para o constante desafio que impele os estudiosos da educação infantil e suas contribuições ao desenvolvimento integral das crianças, que é de refletir e traçar proposições para que o ensino de crianças menores de seis anos não seja forjado em um movimento que, mesmo se atualizando, convive com fragilidades históricas tal como a defesa de um princípio de que a função pré-escolar é a promoção da simples sociabilidade das crianças, prescindindo da mediação dos conhecimentos historicamente produzidos.

Inspirados na mitologia de Prometeu indicamos que nossas proposições neste texto, têm por objetivo oferecer contribuições ao campo da Educação Infantil, que precisa resistir às tendências hegemônicas de reduzir a atividade docente a uma seara de práticas informais com a prevalência dos conhecimentos cotidianos em detrimento dos não cotidianos. A mitologia nos conta que após enganar Zeus, fazendo-o escolher as piores partes de um touro sacrificial, o titã Prometeu viu sua criação, a humanidade, ser punida graças à intolerância de um tirano, mas nem assim desistiu de garantir ao homem a supremacia sobre todos os outros animais viventes. A devolução aos humanos do fogo, representação figurativa do conhecimento, custou caro, Prometeu foi acorrentado nas montanhas do Cáucaso, destinado a ter seu fígado devorado por abutres (ou em algumas versões, uma águia), um castigo infindável devido ao 
poder de regeneração do órgão. Por interseção de Hércules, Prometeu foi libertado de seu martírio anos mais tarde, porém, o caráter épico cabe, verdadeiramente, à semelhança entre ficção e realidade: a certeza de que o homem detém o conhecimento e faz dele suas amarras ou seus heróis.

É nesse sentido, do conhecimento como o que nos liberta ou nos condena que o famoso mito grego parece replicar aspectos que se repetem ao longo da história. A defesa de práticas educativas comprometidas com o pleno desenvolvimento das crianças está assim representada no mérito de Prometeu, um ser mítico. Nele está contido o ideal de esperança, a promessa árdua de uma mudança lenta e gradual, capaz de diminuir as desigualdades culturais que condenam uma parcela de crianças, atendidas nas redes públicas de ensino, a um lento e gradual processo de exclusão social.

\section{REFERÊNCIAS}

ABRAMOVAY, M.; KRAMER, S. O rei está nu: um debate sobre as funções da pré-escola. Cadernos Cedes, Campinas, n. 9, p. 27-38, 1991.

ALVARENGA, V. C. A carreira das professoras de educação infantil: indícios de precarização e intensificação do trabalho docente. In: ARCE, A; JACOMELI, M. R. M (Org.). Educação Infantil versus Educação Escolar? Entre a (des) escolarização e a precarização do trabalho pedagógico nas salas de aula. Campinas, SP: Autores Associados, 2012. p. 151-173.

BARBOSA, E. M. Educar para o desenvolvimento: críticas a esse modelo em consolidação na educação infantil. 2008. 198 f. Tese (Doutorado em Educação Escolar) - Faculdade de Filosofia, Ciências e Letras, Universidade Estadual Paulista, Araraquara, 2008.

CAMPOS, M. M. Educação Infantil: o debate e a pesquisa. Caderno de Pesquisa, São Paulo, n. 101, p. 113-127, jul. 1997.

ELKONIN, D. Psicologia do jogo. Trad. Álvaro Cabral. 2. ed. São Paulo: Martins Fontes, 2009.

ELKONIN, D. Sobre el problema de la periodización del desarrollo psíquico en la infancia. In: DAVIDOV, V; SHUARE, M. (Org.). La psicología evolutiva y pedagógica en la URSS (antología). Moscou: Progresso, 1987. p. 125-142.

ELKONIN, D. Toward the problem of stages in the mental development of children. Journal of Russian and East European Psychology, New York, v. 37. n. 6, p. 11-30, nov./dez. 1999.

ESCUDEIRO, C. M.; BARBOSA, E. M; SILVA, J. C. O desenho infantil de crianças de três anos e sua articulação com os rudimentos da escrita. Revista Ibero Americana de Estudos em Educação, Araraquara, v. 11, n. esp. 4, p. 2287-2305, 2016. DOI:

https://doi.org/10.21723/riaee.v11.n.esp4.9194

RPGE- Revista on line de Política e Gestão Educacional, Araraquara, v. 25, n. 1, p. 267-281, jan./abr. $2021 . \quad$ e-ISSN:1519-9029 
LEONTIEV, A. N. Os princípios psicológicos da brincadeira pré-escolar. In: VIGOTSKII, L. S.; LURIA, A. R.; LEONTIEV, A. N. Linguagem, desenvolvimento e aprendizagem. Trad. Maria da Penha Villalobos. 10. ed. São Paulo: Ícone, 2006b. p. 119-142.

LEONTIEV, A. N. Uma contribuição à teoria do desenvolvimento da psique infantil. In: VIGOTSKII, L. S.; LURIA, A. R.; LEONTIEV, A. N. Linguagem, desenvolvimento e aprendizagem. Trad. Maria da Penha Villalobos. 10. ed. São Paulo: Ícone, 2006a. p. 59-84.

LURIA, A. R. Pensamento e linguagem: As últimas conferências de Luria. Trad. Dlana Myriam Lichtenstein e Mário Corso. Porto Alegre: Artes Médicas, 1986.

MARTINS, L. M. O Ensino e o Desenvolvimento da Criança de Zero a Três Anos. In ARCE, A; MARTINS, L. M. (Org.). Ensinando aos pequenos de zero a três anos. Campinas: Alínea, 2009. p. 93-122.

MARTNS, L. M.; PASQUALINI, J. C. Currículo por campos de experiência na educação infantil: ainda é possível preservar o ensino desenvolvente? Revista online de Política e Gestão Educacional, Araraquara, v. 24, n. 2, p. 425-447, maio/ago. 2020. DOI: https://doi.org/10.22633/rpge.v24i2.13312

SAVIANI, D. Pedagogia histórico-crítica: primeiras aproximações. 11. ed. Campinas: Autores Associados, 2012.

SILVA, J. C; HAI, A. A. O impacto das concepções de desenvolvimento infantil nas práticas pedagógicas em salas de aula para crianças menores de três anos. Perspectiva, Florianópolis, v. 30, n. 3, p. 1099-1123, set./dez. 2012. DOI: http://dx.doi.org/10.5007/2175795X.2012v30n3p1099

\section{Como referenciar este artigo}

BARBOSA, E. M.; SILVA, J. C. Proposições preliminares para organização do ensino na pré-escola. Revista on line de Política e Gestão Educacional, Araraquara, v. 25, n. 1, p. 267-281, jan./abr. 2021. e-ISSN:1519-9029. DOI: https://doi.org/10.22633/rpge.v25i1.14206

Submetido em: 19/09/2020

Revisões requeridas em: 20/11/2020

Aprovado em: 26/12/2020

Publicado em: 02/01/2021 